\title{
Study on Objective-total Cost Management Mode of Construction Project
}

\author{
Shu-Min NIE ${ }^{1, a,{ }^{*}}$, Feng REN ${ }^{2, b}$, Xiao-Liang LIU ${ }^{3, c}$ \\ ${ }^{1}$ School of Resourses and Environment, University of Jinan, Jinan, China \\ ${ }^{2}$ School of Civil Engineering and Architecture, University of Jinan, Jinan, China \\ ${ }^{3}$ Jinan Sijian Group Construction CO.LTD, Jinan, China \\ afo_niesm@ujn.edu.cn, bcea_renf@ujn.edu.cn, chaina578@sina.com
}

Keywords: Construction project, Objective-total cost management, Objective-cost planning.

\begin{abstract}
Based on the basic theory of objective-cost management and combined with the actual situation of cost management of Jinan H Construction Group Ltd., this paper studied the applications of objective-cost management, activity cost management and total cost management in construction enterprises in China and built project cost management mode of construction enterprises based on objective-total cost management system, which has enriched and improved the research of construction project cost management of construction engineering.
\end{abstract}

\section{Introduction}

Currently, price competitions among construction projects both at home and abroad are increasingly fierce, and one of the core factors of price competition is costs. If construction enterprises want to survive and develop in the fierce competition, they must establish a set of comprehensive and advance cost management measures to effectively control costs and improve the competitiveness of enterprises. Only if they innovate and practice in the cost management mode of construction projects, can they find cost management measures that are in conformity with the characteristics of construction projects.

\section{Objective-total Cost Management Mode of Construction Projects}

Cost management of project construction is a closed-loop controlled system which is formed by the value chains and activity chains. In this system, the input variables include the means of labor, object of labor and labor in the form of value, and the output variables are total cost of product and unit cost of product based on a certain yield of product. For objective-total cost management system, it organically combines objective cost management with activity cost management and total cost management, and it gradually accomplishes activity cost management and gradually realizes the activity cost management under objective cost system by building an objective cost system of all personnel, all processes and all dimensions at the activity level.

The whole system consists of the subsystem of objective-cost planning, the subsystem of cost process control and the subsystem of cost accounting and performance evaluation, and its system model is as shown in Fig.1.

Subsystem of objective-cost planning. The main goal of subsystem of objective-cost planning is to cooperate with the total objectives of project and the project management planning, to establish activity center, determine the standard of activity cost control, and break down indicators to respective responsible unit and individual. In the objective control of activity cost, the activity centers are taken as benchmark to implement objective cost, requirements of cost control are proposed to respective activity centers by objective cost, and all activities of project management will be carried out with focus on objective cost[1]. 


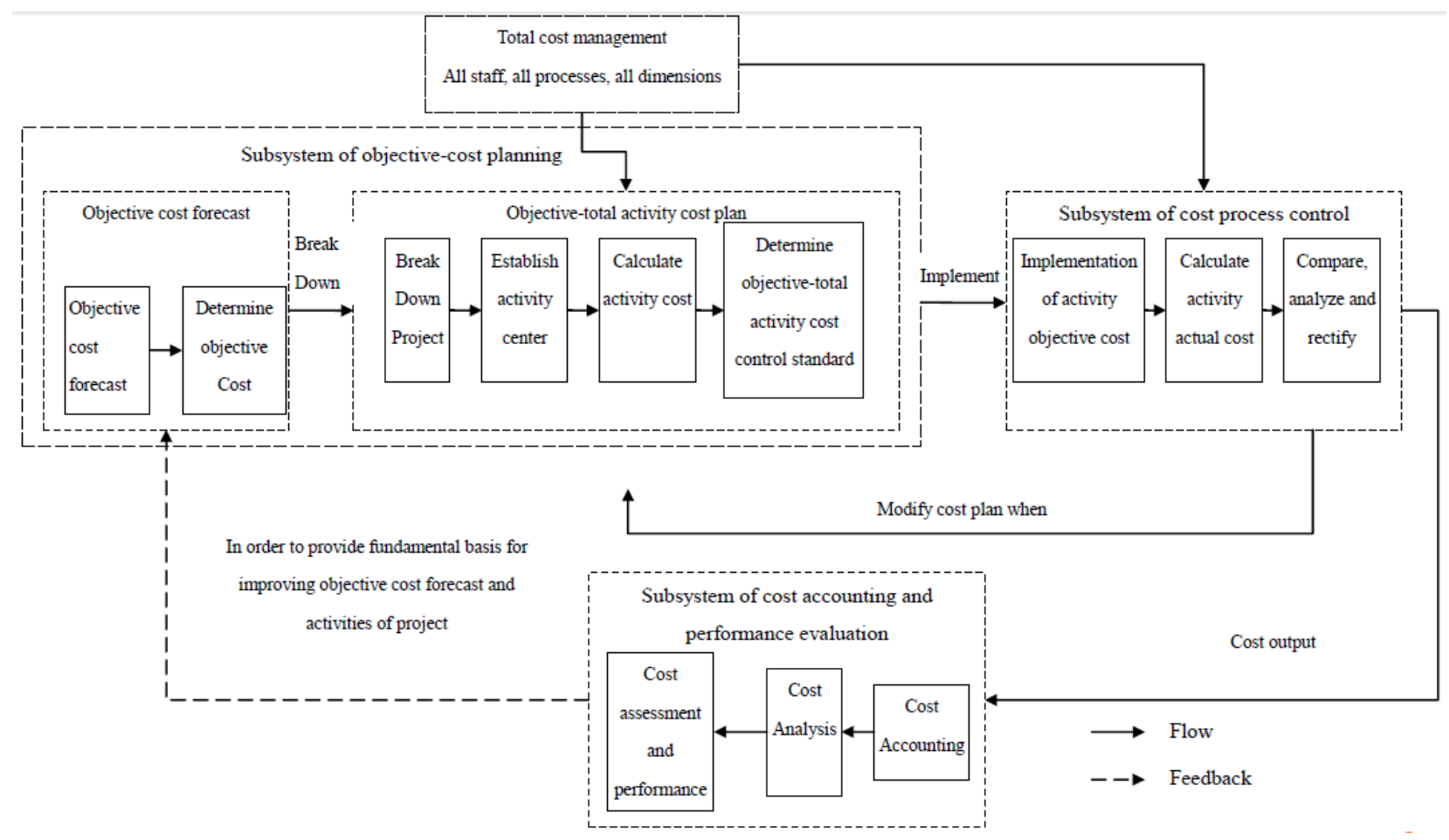

Fig.1 The chart of objective-total cost management system

Subsystem of cost process control . Cost process control is the process of achieving objective cost. Through cost management activities and the actual activity cost calculation, it specifically takes measures to control and reduce costs. Actual activity costs are obtained from the sub-ledger of project and then are allocated to activity centers according to certain methods. Then accurate cost information can be provided by activity cost calculation.

Subsystem of cost accounting and performance evaluation. The subsystem of cost accounting and performance evaluation includes the cost accounting, the cost analysis and the cost assessment and performance evaluation.

Cost accounting is the fundamental basis for performing cost analysis and cost assessment of construction project, as well as an important source of information required for cost forecast, the formulation of cost plan and implementation of cost control. The realizations of cost objectives of project can only be finally inspected by cost assessment.

The basis of cost analysis is cost accounting. The essence of costs can be seen through cost analysis, by which the transparency and controllability of the project cost are enhanced, creating conditions for strengthening cost control and realizing the activity cost objectives and the total cost objectives of project.

The purpose of cost assessment and performance evaluation is to implement the principle of combination of responsibilities, powers and interests to motivate the enthusiasm of all staff to get involved in cost management, summarize experiences and lessons learned from cost management, and better accomplish the cost objectives of construction project[2].

\section{Application of Objective-total Cost Management Mode of Construction Project}

Project Overview. In order to promote the objective-total cost management mode and verify the correctness of the theory, experiments are made in the immediate project department of the Jinan $\mathrm{H}$ Construction Group Ltd., and the experimental project is a certain office building project with contract price of 48.55 million.

The immediate project department was established in 2001 with the existing management staff of 40 people. From its establishment to now, its total output value is 475 million with project cost of 418 million Yuan, yielding profits of 41 million Yuan and a rate of profit of 8.6\%. 
Practices of Objective-total Cost Management Mode of Construction Project in Engineering Project Management. In accordance with the theory of objective-total cost management mode, the project management team of the works mainly conducted applied research in the following aspects.

According to the contract price, construction drawings and bill of quantities in bidding documents, the enterprise determined responsibility objective costs of project managers. The project cost of the construction contract was 48.55 million Yuan and it was required to pay 1.602 million Yuan for tax. Then the responsibility objective cost of project managers was 44.52 million.

Through organizing the preparation of the project management and implementation planning, the project managers sought ways to reduce costs, and they organized the preparation of construction budget to determine that the planned objective cost of the project was 43.064 million Yuan. They took such amount as the basis of cost objective control of the project.

Based on the theory of objective-total cost management mode and using WBS method, construction task breakdown was performed against the whole construction project according to the unit project, sub-unit project and item project. Table 1 shows the project breakdown of construction and installation.

Table 1 The project breakdown of construction and installation

\begin{tabular}{|c|c|}
\hline Level 2 & Level 3 \\
\hline $\begin{array}{l}\text { G/01 Precipitation works, } \\
\text { earthwork and slope } \\
\text { protection works }\end{array}$ & $\begin{array}{l}\text { G/01.01 Operation of subpackage project contract } \\
\text { G/01.02 Performance of contract }\end{array}$ \\
\hline $\begin{array}{l}\text { G/02 Underground } \\
\text { Structure }\end{array}$ & $\begin{array}{l}\text { G/02.01 Check of foundation subsoil } \\
\text { G/02.02 Construction of bedding, water-proof layer and bottom plate } \\
\text { G/03.01 Structure construction of the first story }\end{array}$ \\
\hline G/03 Main structure & $\begin{array}{c}\text { G/03.02 Structure construction of the second story } \\
\ldots \ldots . .\end{array}$ \\
\hline ...... & $\cdots \cdots$ \\
\hline G/13 Exterior finishes & $\begin{array}{l}\text { G/13.01 Operation of exterior finishes construction contract } \\
\text { G/13.02 Performance of exterior finishes construction contract }\end{array}$ \\
\hline
\end{tabular}

Based on departments or production and operation segments etc., the main activities in such departments or production and operation segments were divided into different activity centers according to coessential activities. The cost-activity centers of main structure construction are shown in Table 2.

Table 2 The cost-activity center of main structure construction

\begin{tabular}{cccc}
\hline \multicolumn{2}{c}{ Activity center } & \multicolumn{2}{c}{ Main activity } \\
\hline \multirow{2}{*}{ No. } & Name & No. & Name \\
\hline \multirow{2}{*}{031} & Concrete work & 011 & Commercial concrete materials \\
& & 012 & Transport of concrete \\
& & $\ldots \ldots$ & $\ldots \ldots$ \\
& & 021 & Reinforcing bar material \\
& Reinforcing bar & 022 & Transport of reinforcing bar \\
& engineering & $\ldots \ldots .$. & $\ldots .$. \\
& & $\ldots . .$. & $\ldots .$. \\
\hline
\end{tabular}

According to planned objective cost and breakdown of projects, project managers had organized their department to conduct a top-down breakdown against planned objective costs and to perform activity cost calculation against respective activity centers. They required that the objects should be break down to the 
level of activity and cost control standard of respective activities should be identified to facilitate the cost control and analysis during construction period.

The focuses of cost management of project bidding and quotation are the final offer resulting from forecast of project cost when bidding as well as the decisions on the terms of the contract related to the project cost in negotiations and execution of contract[3]. The cost decision-making of this phase often is the prerequisite factors of profit or loss of project and is the source of project cost management.

According to component of the project cost and the type of resources invested, the cost management of engineering project was classified into four categories including labor costs, material costs, machinery costs and management fees.

Cost pool means the accumulation center of resources consumed by activities. Each cost pool accumulates the cost of activity center it represents. In order to reduce the workload of cost accounting, cost drivers can be consolidated, and the relevant resource costs may be consolidated into the cost of homogeneous nature according to quality of the cost drivers. Table 3 is quantity of resource driver in concrete on some day after the combination.

Table 3 The quantity of resource driver in concrete

\begin{tabular}{cccc}
\hline Cost & Activity cost pool & Resource driver & Consumption \\
\hline Concrete construction costs & Material activity center & Work amount & $2500 \mathrm{~m} 3$ \\
Concrete construction costs & Equipment activity & Amount of unit per & 2 unit/shift \\
Concrete construction costs & Labor activity center & Amount of labor & 150 work day \\
Concrete construction costs & Quality activity center & Quantity of spot check & 50 lots \\
\hline
\end{tabular}

When the original documents are passed to the financial sector, the financial sector will prepare cost entries in accordance with accounting standards at first. In the end of each month, the cost accounting system will collect information to generate summary table of activity center costs.

In project accounting system, project management team became the responsibility center of project accounting, was fully responsible for comprehensive accounting of the engineering project, and performed overall control, supervision and assessment against all the input and output of the project. Through analyzing and summarizing the profit and loss of the planned objective costs and the actual cost of engineering project, they mastered the use and inputs of people, materials and machines. They periodically prepared cost statement and analyzed materials and project completion costing sheet to control project funds and expenses.

With the progress of construction of the project, cost analysis was dynamically carried out in various forms, and it was combined with the operation and management of various activity centers and various factors of production. On the basis of assessment and analysis, the project managers prepared monthly project cost report and submitted it to the cost management department of the enterprise for inspection, guidance and assessment.

Cost assessment of the project was assessed in combination with achievements of responsibility objective cost and planned objective cost. Comprehensive rating was performed in accordance with the accomplishment of objectives and implementation of the control standards as well as work performance of cost management, and economic rewards and punishments were timely imposed on cost accomplishments to motivate the enthusiasm of all staff to be involved in cost management.

Summary of Applications. The pilot project started in October of that year and was completed in September of the second year. After the assessment of the company, quality objectives, safety objectives and environmental and civil construction objectives had reached the requirements of objective responsibility statement. The contract project cost was 48.55 million with the taxes of 1.602 million, actual costs of $41,996,000$, profit of 4.952 million and rate of profit of $10.2 \%$. The rate of profit not only exceeded $5 \%$, the responsibility profit objective set by the Group, but also $8 \%$, the planned profit object of the project management team, with significant economic benefits. 
- The advantage of objective-total cost management mode of construction project is the combination of the responsibility objectives, plan objectives and activities, making the cost of the smallest unit of cost management more manageable.

- It provides a good calculation model for the performance evaluation of activity so that the entire personnel objective responsibility system can be implemented better.

- Through the analysis of cost drivers and cost accounting, it provides quantitative means in terms of cost for optimization of the construction scheme and improvement of workflow.

- The cost management information formed can better serve the cost forecast of construction project, and at the same time the information is an important source of information required for the development of plans and implementation of cost control.

\section{Summary}

In the mode of combination of theoretical research and empirical research and based on the theory of objective management, activity cost management and total cost management, this paper built objective-total cost management mode of construction project, and practiced and applied in the engineering project of Jinan H Construction Group Ltd. It broke down and implemented objective cost indicator according to activity chains at each level by analysis of cost drivers and activity analysis to realize the objectives of total cost management, achieving significant economic benefits.

\section{Acknowledgement}

The author would like to thank for the support from the Jinan science and technology plan projects (NO.: 201201142) and the national natural science fund projects (NO.: 51208228) of China.

\section{References}

[1] Wu Xuedi. Research of Total Cost Management of Construction Enterprise [D] Hangzhou: Zhejiang University, 2003.

[2] Nie Shumin. Owner's Cost Control in Construction Phase of Construction Project [J], Shandong Finance Institute Journal, 2002, 2:77-80.

[3] Tian Maohua. Cost Management Mode and Application Research on Modern Enterprise Objective [D]. Xi'an: Xi'an University of Architecture and Technology, 2005. 